\title{
OPTIMAL LOCATION AND SIZING OF SVC CONSIDERING SYSTEM LOSSES, VOLTAGE DIVISION AND SYSTEM OVERLOAD
}

\author{
H. A. M. Kanaan, M. M. EL-Gazaar, and M. A. A. Mehanna \\ Electrical Engineering Department, Faculty of Engineering, Al-Azhar University, Nasr City, \\ Cairo, Egypt. \\ *Corresponding author E-mail: hamdy.mohamed@azhar.edu.eg
}

\begin{abstract}
:
Flexible Alternating Current Transmission Systems (FACTS) devices have been suggested as an efficient solution for regulating bus voltage and controlling in power flow in electrical power networks, which leads to improve stability and reduce the loss of electrical power. Suitable location and the appropriate size of these devices can lead to control line flow and maintain the voltage at each bus at the desired level and so recover system security. This paper shows comparison study between two techniques from artificial intelligent techniques to determine location and optimal size of FACTS devices based on power losses, voltage division and system over load. Also, in this paper a comparison between multi- and single objective function to find the optimal location and optimal size of SVC has been carried out. The proposed algorithms are simulated annealing and particle swarm optimization and are tested on modified IEEE 30-bus power system for optimal allocation of Static VAR Compensator (SVC) as a kind of FACTS devices and results are presented.
\end{abstract}

Keywords: Flexible Alternating Currents Transmission System (FACTS), Static VAR Compensator (SVC), Multi-objective Optimization Problem (MOP), Simulated Annealing (SA), Particle Swarm Optimization (PSO).
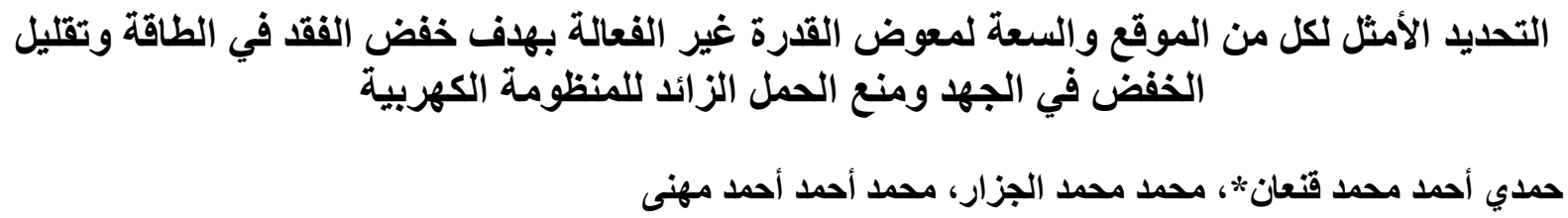

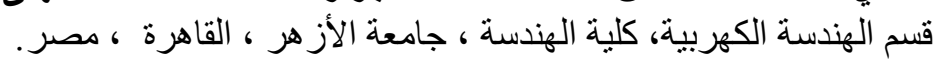

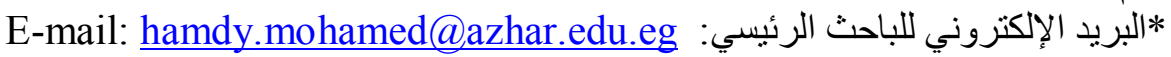

\footnotetext{
الملخص

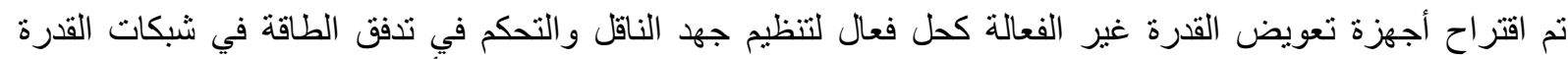

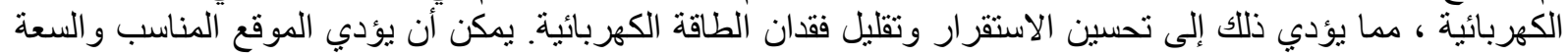

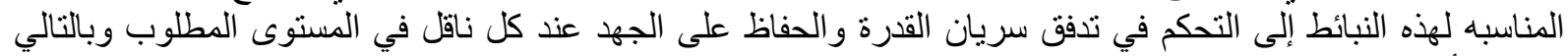

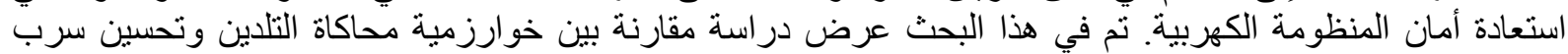

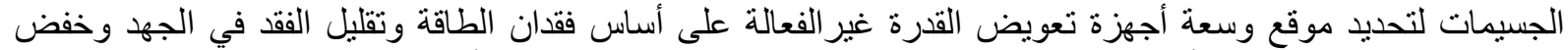

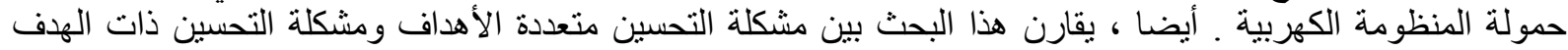
الواحد للعثور على الموقع والسعة المثلي لمعوض القدرة غير الفعالة. وقد تم اختبار الخوارزمية المقترحة على منظومة
} 


$$
\text { عرض نتائج هذا الإختبار. المع والسعة المثلي لمعوض القدرة غير الفعالة كنوع من أجهزة تعويض القدرة غير الفعالة وقد نم }
$$

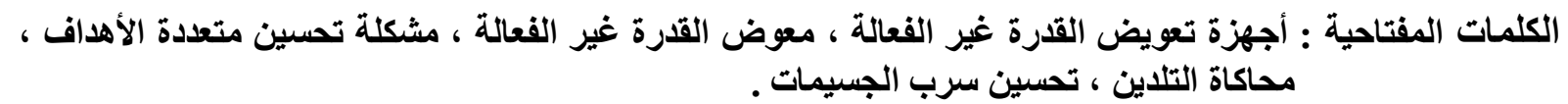

\section{1-INTRODUCTION}

As the load increases, power utilities are trying to find ways to maximize the utilization of their existing transmission systems, hence controlling the power stream in the transmission lines is a vital issue in planning and operating of power system network.

Flexible alternating current transmission system (FACTS) devices are utilized to preserve pliant operation of the power system from power generation area to the distribution area, FACTS devices play considerable role in boost the dynamic and static behavior of electrical systems. There are diverse kinds of FACTS devices, such as Static VAR Compensator (SVC), Thyristor controller series compensator (TCSC), Static Synchronous Series Compensator (SSSC), Static Synchronous Compensator (STATCOM), Thyristor Controlled Phase Shift Transformer (TCPST), Thyristor Controlled voltage Regulator (TCVR), Optimal Unified Power Flow Controller (OUPFC), Interlink Power Flow Controller (IPFC) and Unified Power Flow Controller (UPFC) [1,2].

The ability of FACTS devices to control those parameters such as shunt admittance, series impedance, voltage drop, bus voltage and phase angle controlling in the operation of transmission system, provides the prospect of improving system operating troubles such as dynamic/static stability, system security, total generation fuel cost, system loadability and so forth. However, this prospect depends mainly on the location, type and sizing of FACTS devices that installed in the power system.

The optimal location and optimal size of FACTS devices has been discussed in various papers considering different problems of system operation and performance. Sensitivity-based approaches have been applied in [3, 4] for this aim. To enhance power system security, the FACTS devices are located at the optimal place based on the sensitivity of security indices to bus voltages or line power flows or system losses, and then the value of the sensitiveness is applied for sizing the FACTS device. Though these approaches display agreeable results for several situation studies, in order to high nonlinearity of equations in power system, there is no surety to the efficiency of first order sensitivities especially for large scale and bulk power systems [5]. Artificial Intelligence techniques (AI) based approach such as genetic algorithms [6], Simulated Annealing (SA) Algorithms [7], particle swarm algorithms [8], Low Discrepancy Sequences (LDS) [9], Differential Evolution (DE) technique [10] and Bacterial Swarming Algorithm (BSA) [11] are successively applied for optimal location and optimal size of FACTS devices problems. The most obvious advantage of using Artificial Intelligence techniques is their ability to find the global optimal solution, but other methods may reach to the local optimal solution.

With regard to multiple-objective problems, there are two different approaches. One of them is to combine individual targets into a single compound function (weighted sum method) [6]. The other approach is to determine a set of optimal solutions (an entire Pareto optimal solution set) $[5,12]$. Although the first approach is very difficult and small disturbances in weights can lead to different outcomes, the second approach does not give better outcomes than single objective problems. In this paper, a multi-objective optimization algorithm based on two techniques from Artificial Intelligent Techniques, which are Simulated Annealing algorithm and Particle Swarm Optimization are applied to set the optimal location and optimal size of SVC device to increase security in power system considering power losses, voltage division and system over load. This paper is regular in six parts as follow: Part 1 explains highlights the brief introduction, problem statements, objective, literature review and the outline of the paper is also given in this part. Part 2 explains FACTS devices, types and SVC is discussed in details. Objective functions are formulated in part 3. In part 4, the SA and PSO for optimal location and optimal size of SVC device are explained. In part 5, 30-bus system is taken as a base case. And finally in part 6 , results and conclusion are given. 


\section{2- FACTS DEVICE}

FACTS devices is static devices utilized for the alternating current (AC) transmission of electrical energy. It is used for increasing controllability and raise poor transfer capability [13]. It devices can be labeled into four groups [13] are:
A. Series connection.
B. Shunt connection.
C. Combined series \& series connection.
D. Combined series shunt connection.

Because of the advantages available in using SVC, such as: cheap, higher-capacity, faster and more reliable. Also, it improved the load power factor, and therefore, reduced line losses and improved system capability [14], we will choose SVC controller in this study.

\section{1- Static VAR Compensator (SVC)}

The SVC is connected with transmission lines in parallel. It is inclusive of a series of controllers are used to absorb or inject reactive power to the system when required. It also comprise of different filters which nominate the harmonics in the power system. Figure 1 shows the simple schematic diagram for SVC. The SVC can be applied as reactive power suppliers while it is linked to the bus [14], it also may be applied for power factor rectification, static and dynamic security enhancement, voltage regulation, damping the fluctuation, reactive power planning, enhanced loadability and loss decreasing [14]. Figure 2 shows the equivalent circuit of the SVC.

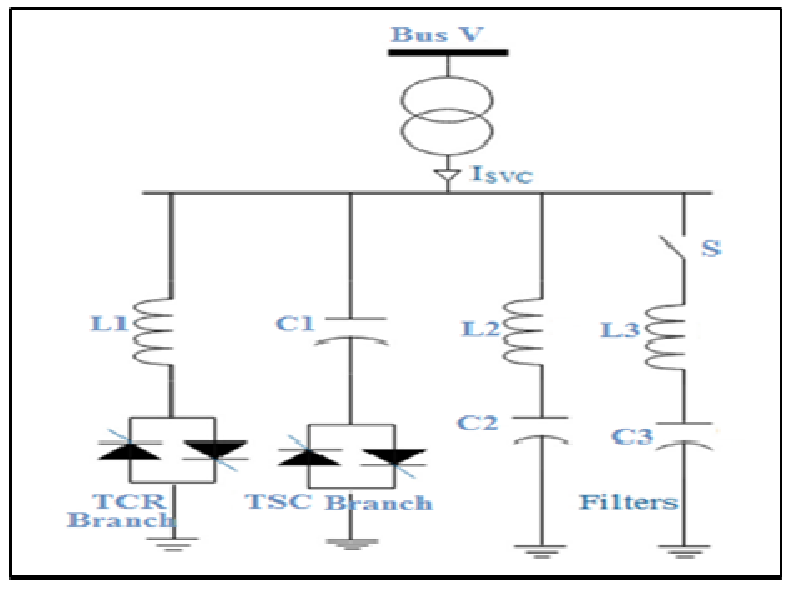

Fig.1 SVC Schematic Diagram

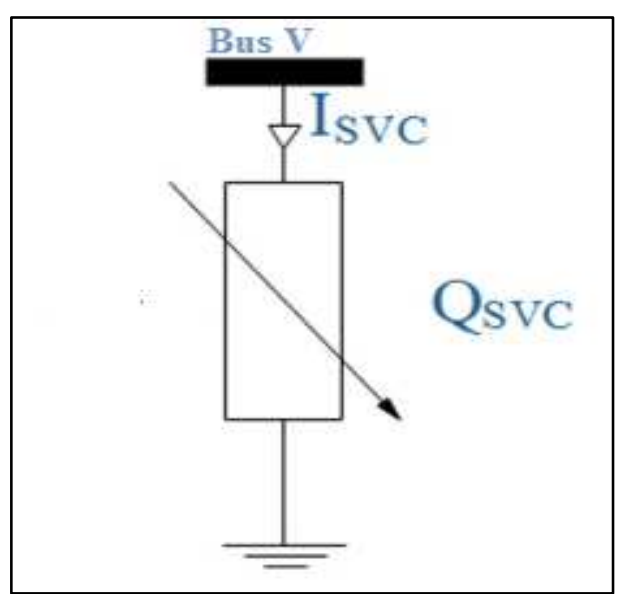

Fig.2 SVC Equivalent Circuit

In this paper the SVC is applied as reactive power suppliers at bus $\mathrm{j}$ : Where the magnitude of $\mathrm{Q}_{\mathrm{sVC}}$ at bus $\mathrm{j}$ in between -100 MVAR and +100 MVAR) [15].

\section{3- PROBLEM FORMULATION}

\section{1- Objective Functions}

The target of optimization was the determination the optimal location and optimal size of SVC device into a power system in order to reduce system losses, voltage division and system over load. Therefore, the problem turn into a multi-objective optimization problem (MOP), and this can be expressed as:

$$
\operatorname{Min} F(x)=\left[F_{V d}(x), F_{P L}(x), F_{o l}(x)\right]
$$

Where $F_{P L}(x), F_{V d}(x)$, and $F_{o l}(x)$ are objective functions, where $F_{P L}(X)$ is real power losses, $F_{V d}(X)$ is voltage deviation and $F_{o l}(x)$ is the system over load as follows: 
Where:

$$
\begin{aligned}
& F_{V d}=\Sigma_{k}\left|\frac{v_{k}-V_{i}^{R E F}}{v_{k}^{R E F}}\right|^{2} \\
& F_{P L}=\operatorname{real}\left(\Sigma_{m=1}^{n} s_{m}\right) \\
& F_{o l}=\Sigma_{m}\left(\frac{s_{m}}{s_{m}}\right)^{2}
\end{aligned}
$$

$V_{i}^{B E F}$ : is voltage magnitude (reference) which assumed 1 pu for all load buses as [5].

$V_{k}$ : is the voltage magnitude for $\mathrm{k}^{\text {th }}$ load bus.

$S_{m}:$ is the apparent power for $\mathrm{m}^{\text {th }}$ line.

$S_{m}^{\max }:$ is the max apparent power for $\mathrm{m}^{\text {th }}$ line.

$S_{m}:$ is the total loss at $m^{\text {th }}$ line.

The multi-objective function can be expressed as put up with:

$$
\operatorname{Min} F(x)=w_{1} F_{V d}(x)+w_{2} F_{P L}(x)+w_{3} F_{o l}(x)
$$

The weight factors $\mathrm{w}_{1}, \mathrm{w}_{2}$ and $\mathrm{w}_{3}$ could be used to accord less or more significance to specific elements of the system. If $\mathrm{w}_{1}>\mathrm{w}_{2}>\mathrm{w}_{3}$ the significance is more to minimum the voltage division than to real power loss and system overload and vice versa. In this paper, the weight factors were specified so as to have the value of the same indicator for three parameters.

\section{2- Constraints}

The optimization issue is limited by the following constraints:

\section{A. Equality Constraints}

Those constraints symbolize the load flow equations conformable to both balance active and reactive power equations, which may be written as:

$P_{G j}-P_{D j}-\Sigma_{M=1}^{N} V_{M}\left[G_{j M} \cos \left(\theta_{j M}\right)+B_{j M} \sin \left(\theta_{j M}\right)\right]=0$

$Q_{G j}-Q_{D_{j}}-\sum_{M=1}^{N} V_{M}\left[G_{j M} \sin \left(\theta_{j M}\right)-B_{j M} \cos \left(\theta_{j M}\right)\right]=0$

Where:

$\mathrm{P}_{\mathrm{Gj}}$ and $\mathrm{Q}_{\mathrm{Gj}}$ : Generator active and reactive power produced at bus $\mathrm{j}^{\text {th }}$ respectively.

$\mathrm{P}_{\mathrm{Dj}}$ and $\mathrm{Q}_{\mathrm{Dj}}$ : Load active and reactive power at bus $\mathrm{j}^{\text {th }}$ respectively.

$B_{j m}$ and $G_{j m}$ : Transfer susceptance and conductance among buses $\mathrm{j}$ and $\mathrm{m}$, respectively.

\section{B. Inequality Constraints}

Generation constraints:

$$
\mathrm{Q}_{\mathrm{Gj}}{ }^{(\min )}<\mathrm{Q}_{\mathrm{Gj}}<\mathrm{Q}_{\mathrm{Gj}}{ }^{(\max )} \text { for } \mathrm{j}=1, \ldots, \mathrm{N}
$$

Transmission constraints:

$$
\mathrm{S}_{\mathrm{m}}{ }^{(\min )}<\mathrm{S}_{\mathrm{m}}<\mathrm{S}_{\mathrm{m}}(\max )
$$

For SVC constraints:

$$
\mathrm{Q}^{(\min )}<\mathrm{Q}_{\mathrm{SVC}}<\mathrm{Q}^{(\max )}
$$

Where:

$\mathrm{Q}_{\mathrm{Gj}}$ : Generator reactive power produced at bus $\mathrm{j}^{\text {th }}$.

$\mathrm{Q}_{\mathrm{Gj}}{ }^{(\min )}, \mathrm{Q}_{\mathrm{Gj}}{ }^{(\max )}$ : Generator minimum and maximum reactive power produced at bus $\mathrm{j}^{\text {th }}$ respectively.

$\mathrm{S}_{\mathrm{m}}$ : The apparent power for $\mathrm{m}^{\text {th }}$ line.

$\mathrm{S}_{\mathrm{m}}{ }^{(\mathrm{min})}, \mathrm{S}_{\mathrm{m}}{ }^{(\max )}$ : Minimum and maximum apparent power for $\mathrm{m}^{\text {th }}$ line respectively. 
$\mathrm{Q}_{\mathrm{SVC}}$ : SVC reactive power produced.

$\mathrm{Q}^{(\min )}, \mathrm{Q}^{(\max )}$ : Minimum and maximum SVC reactive power produced respectively.

\section{4- ALGORITHMS AND TECHNIQUES TO SET THE OPTIMAL LOCATIONS AND SETTINGS OF SVC.}

It is taken into consideration that the optimal location and optimal size of various FACTS devices can be highly constrained, multimodal and complex optimization problems. There are four categories to determine the optimal location and optimal size of the FACTS devices in terms of the optimal location and optimal size. These categories are analytic approximation, conventional optimization method, hybrid manner and finally meta-heuristic optimization techniques [16]. In this section, Simulated Annealing Algorithm (SA) and Particle Swarm Optimization (PSO) are discussed in detailed as a technique from Meta-heuristic optimization techniques.

Meta-heuristic optimization techniques are the most commonly used methodologies to determine the optimal location and optimal size of FACTS devices. They are stochastic, population-based optimization algorithms that are highly efficient in dealing with a multimodal, highly constrained, multi-objective and discrete system [2].

\section{1- Simulated Annealing}

The SA algorithm is a technique that basically depends on random research to solve improvement problems, and it simulates physically the process of cooling metals in the form of a pure crystal to obtain pure metal (less energy and a large crystalline volume) to reduce defects in the metal. The simulated annealing will coincide to its global optimality if sufficient randomness is applied in combination with so slow cooling [17].

The basic idea of this algorithm in random search depends on the Markov chain [18]. The cooling schema of this algorithm can be separated to four ingredients [18].

1) Starting Temperature.

2) Final Temperature

3) Temperature Decrement

There are four different ways to decrement the temperature [18].

i. Linear:

$$
T_{I}=T_{0}-J \beta
$$

Where $\beta$ is constant

ii. Geometric:

$$
T_{I+1}=\alpha T_{J}
$$

Where $\alpha$ is a coefficient caries from zero to 1 .

iii. Logarithmic:

$$
T_{J}=\frac{T_{0}}{\log (n}
$$

iv. Very slow decrease: 


$$
T_{I+1}=\frac{T_{I}}{1+\beta T_{I}}
$$

\section{4) Iterations at Each Temperature}

\section{2-SA Algorithm}

In optimization issues, the simulated annealing (SA) algorithm is utilized to find out the global minimum of a problem with many variables. The following flowchart is used to describe the sequence of steps for SA algorithm [19]:

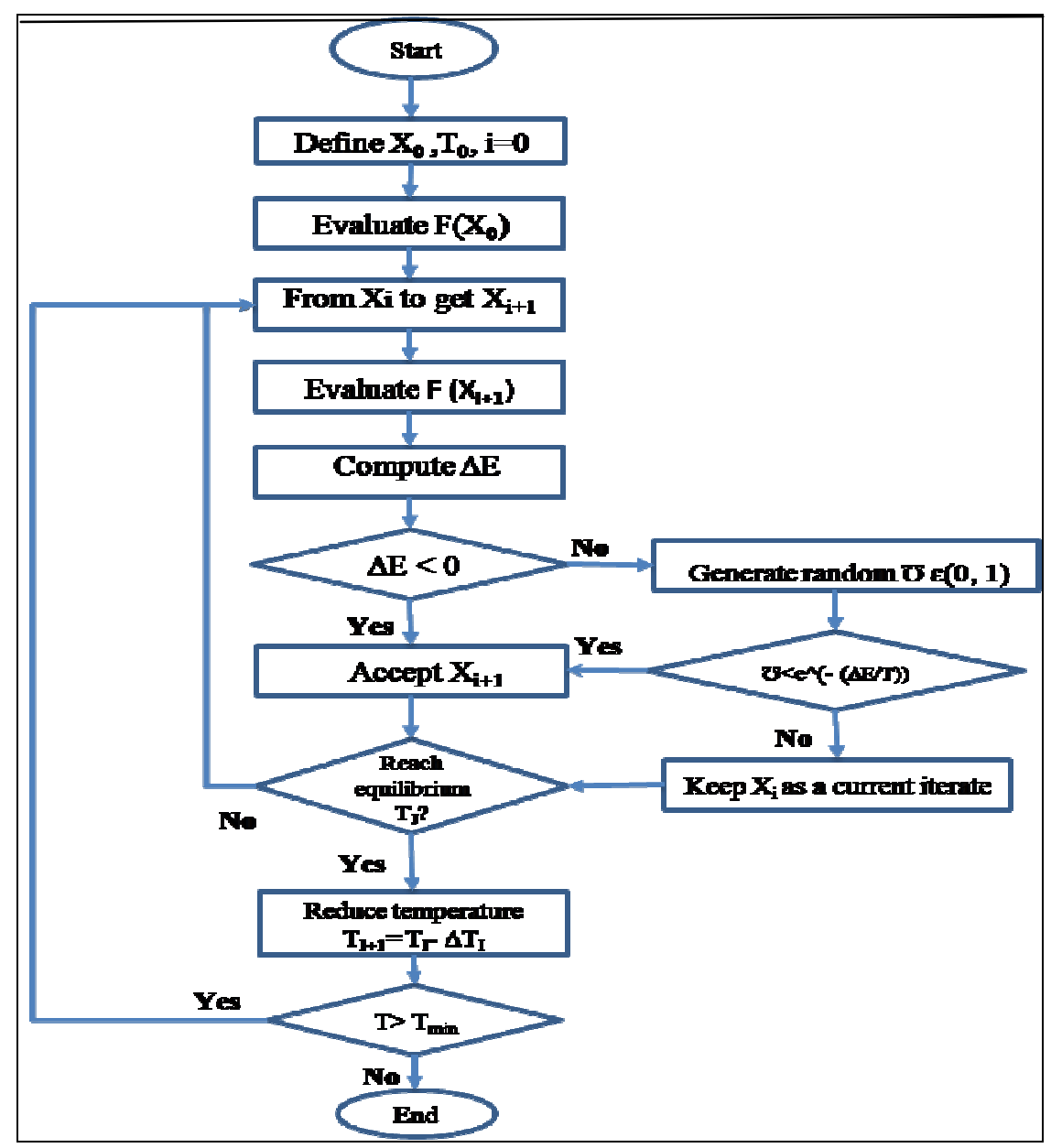

Fig.3 The Flow Chart for Simulated Annealing Optimization

\section{3- Particle Swarm Optimization (PSO)}

Particle Swarm Optimization (PSO) is inhabitance-based optimization appliance, which can be executed and applied readily to fix diverse function optimization problems, or solve the problems that may be converted to optimization problems. As an algorithm technique, the major power of Particle Swarm Optimization (PSO) is its quick concourse, which matches favourably with much global optimization techniques like Simulated Annealing (SA), Bees Algorithm, Genetic Algorithms (GA) and another global optimization algorithm technique [20]. The major merit of the Particle Swarm is that it has to deal with little parameters. Several of the PSO algorithm's parameters comprise search space size, particle size, acceleration training factors or coefficients and termination criterion [20]. The following flowchart is used to describe the sequence of steps for PSO algorithm [21]: 


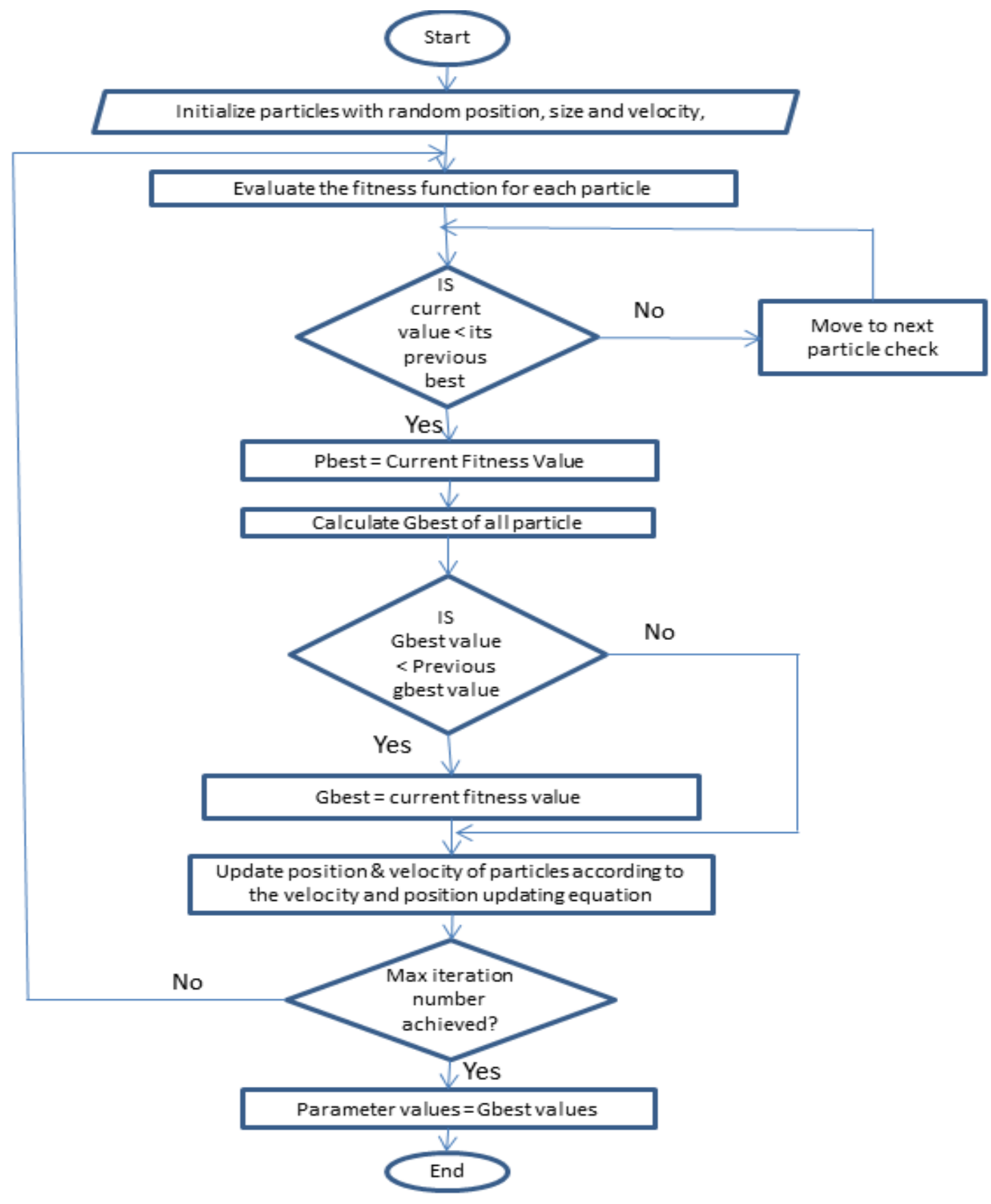

Fig.4 The Flow Chart for Particle Swarm Optimization

This paper compares between SA algorithm and PSO to determine the optimal location and optimal size of SVC to enhance system security.

\section{5- TEST SYSTEM}

The system under study is 30-bus system that is data are based on 100 MVA, which consists of six generator buses (bus 1 is slack bus and buses 2, 13, 23, 22 and 27 are PV-bus), the system has 20 stationary loads totaling 265.16 MW and 150.64 MVAR, real and reactive power loads, respectively. The algorithm of this strategy was programmed in MATLAB. The 30-bus system is appeared in Figure ${ }^{\circ}$. 


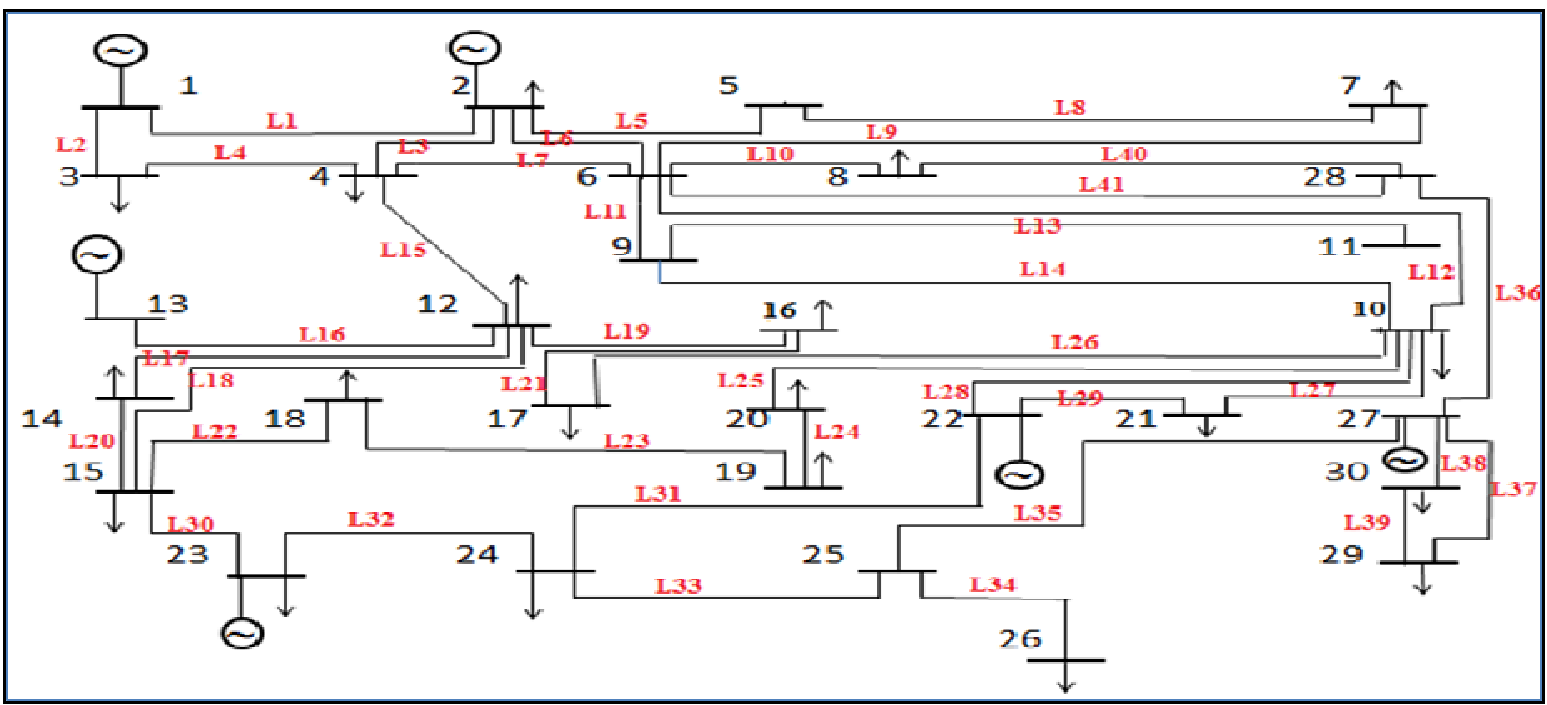

Fig.5 Modified of IEEE- 30 Bus System

For Simulation studies, five different scenarios are to be considered for 30-bus test system:

Scenario 1: Run power flow of the system at normal operation (without installation of SVC device) and find all of three objectives.

Scenario 2: The SA algorithm with single objective function will be applied in case of one $\mathrm{SVC}$ is installed and compare the results with scenario 1.

Scenario 3: Then return scenario 2 but with the Multi-Objective SA using all three objectives. Scenario 4: Repeat scenarios 2, 3 but using PSO instead of SA algorithm.

Scenario 5: Survey the impact of optimal location and optimal size for SVC on the three objectives in the system using the best algorithm, whether it is a SA or PSO.

\section{6- RESULTS}

Table 1 gives the voltage deviation, total real power losses, and system overload of 30-bus system without put up SVC device (scenario 1), thereafter the SA algorithm is applied to set the SVC at the optimal location and optimal size. SA is applied three times for three objectives as a single objective function (scenario 2), and in all time the outcomes are presented.

Table 1: Optimal Location and Sizing of SVC Using SA

\begin{tabular}{|c|c|c|c|c|c|}
\cline { 3 - 6 } Objective & Location & $\begin{array}{c}\text { Size } \\
\text { MVAR }\end{array}$ & $\begin{array}{c}\text { Voltage } \\
\text { division }\end{array}$ & $\begin{array}{c}\text { Real losses } \\
\text { (MW) }\end{array}$ & $\begin{array}{c}\text { System } \\
\text { overload }\end{array}$ \\
\hline w/o SVC & ---- & --- & 0.0324 & 7.4418 & 2.3610 \\
\hline With SVC & Bus & Q $_{\text {sVC }}$ & & & \\
\hline Power losses only & 8 & 57.1413 & 0.0170 & 6.7258 & 2.0915 \\
\hline $\begin{array}{c}\text { Voltage division } \\
\text { only }\end{array}$ & 6 & 99.4545 & 0.0128 & $\mathbf{6 . 9 3 2 5}$ & 2.2616 \\
\hline $\begin{array}{c}\text { System overload } \\
\text { only }\end{array}$ & 8 & 46.8799 & 0.0189 & 6.7472 & 2.0817 \\
\hline
\end{tabular}

The major observation of table 1 is that the ideal solution for one function is not a perfect solution for another objective.

In scenario 3 the single objective problem turnover a multi-objective optimization functions (MOP). 
Table 2 displays the multi-objective SA is used to find the optimal location and optimal size of SVC. SA algorithm is applied only one time for three objectives as a multi-objective duty and the outcome is presented.

Table 2: Optimal Location and Sizing of SVC Using MOP-SA

\begin{tabular}{|c|c|c|c|c|c|}
\cline { 3 - 6 } \multicolumn{2}{c|}{} & \multicolumn{3}{c|}{ Results } \\
\hline Objective & Location & $\begin{array}{c}\text { Size } \\
\text { MVAR }\end{array}$ & $\begin{array}{c}\text { Voltage } \\
\text { division }\end{array}$ & $\begin{array}{c}\text { Real losses } \\
\text { (MW) }\end{array}$ & $\begin{array}{c}\text { System } \\
\text { overload }\end{array}$ \\
\hline SVC & Bus & Q svc & & & \\
\hline $\begin{array}{c}\text { PL\& V.D and } \\
\text { system overload }\end{array}$ & 8 & 72.8868 & 0.0148 & 6.573 & 2.1528 \\
\hline
\end{tabular}

The major observation of table 2 is that using MOP-SA leads to controlling all three parameters together.

Table 3 displays the PSO algorithm to set the SVC at the optimal location and optimal size. PSO is applied three times for three objectives, and in all time the outcomes are presented.

Table 3: Optimal Location and Sizing of SVC Using PSO

\begin{tabular}{|c|c|c|c|c|c|}
\cline { 3 - 6 } \multicolumn{2}{|c|}{} & \multicolumn{3}{c|}{ Results } \\
\hline Objective & Location & $\begin{array}{c}\text { Size } \\
\text { MVAR }\end{array}$ & $\begin{array}{c}\text { Voltage } \\
\text { division }\end{array}$ & $\begin{array}{c}\text { Real losses } \\
\text { (MW) }\end{array}$ & $\begin{array}{c}\text { System } \\
\text { overload }\end{array}$ \\
\hline SVC & Bus & Q svC & & & 2.0917 \\
\hline $\begin{array}{c}\text { Power losses } \\
\text { only }\end{array}$ & 8 & 57.159 & 0.017 & 6.7258 & 2.2633 \\
\hline $\begin{array}{c}\text { Voltage } \\
\text { division only }\end{array}$ & 6 & 100 & 0.0127 & 6.9358 & 2.0816 \\
\hline $\begin{array}{c}\text { System } \\
\text { overload only }\end{array}$ & 8 & 47.8618 & 0.0187 & 6.7433 & \\
\hline
\end{tabular}

From tables 1 and 3, it is clear that there is no difference between the PSO and SA algorithm in determining the minimum power losses, but the PSO is better than SA algorithm in determining the lowest value in both cases voltage division and system overload. Moreover, PSO faster than SA algorithm access to global minimum point.

Table 4 displays the multi-objective PSO is used to find the optimal location and optimal size of SVC. PSO algorithm is applied only one time for three objectives as a multi-objective duty and the outcome is presented.

Table 4: Optimal Location and Sizing of SVC Using MOP-PSO

\begin{tabular}{|c|c|c|c|c|c|}
\cline { 3 - 6 } \multicolumn{2}{c|}{} & \multicolumn{3}{c|}{ Results } \\
\hline Objective & Location & $\begin{array}{c}\text { Size } \\
\text { MVAR }\end{array}$ & $\begin{array}{c}\text { Voltage } \\
\text { division }\end{array}$ & $\begin{array}{c}\text { Real losses } \\
(\text { MW) }\end{array}$ & System overload \\
\hline SVC & Bus & Q svC & & & \\
\hline $\begin{array}{c}\text { PL\& V.D and system } \\
\text { overload }\end{array}$ & 8 & 70.032 & 0.0152 & 6.7581 & 2.1376 \\
\hline
\end{tabular}

The major observation of table 4 is that using MOP-PSO leads to controlling all three parameters together. 
Figure 6 displays the effect of SVC at optimal location and optimal size on the voltage profile in the system under study. From this figure, it is noted that SVC improve the voltage situation.

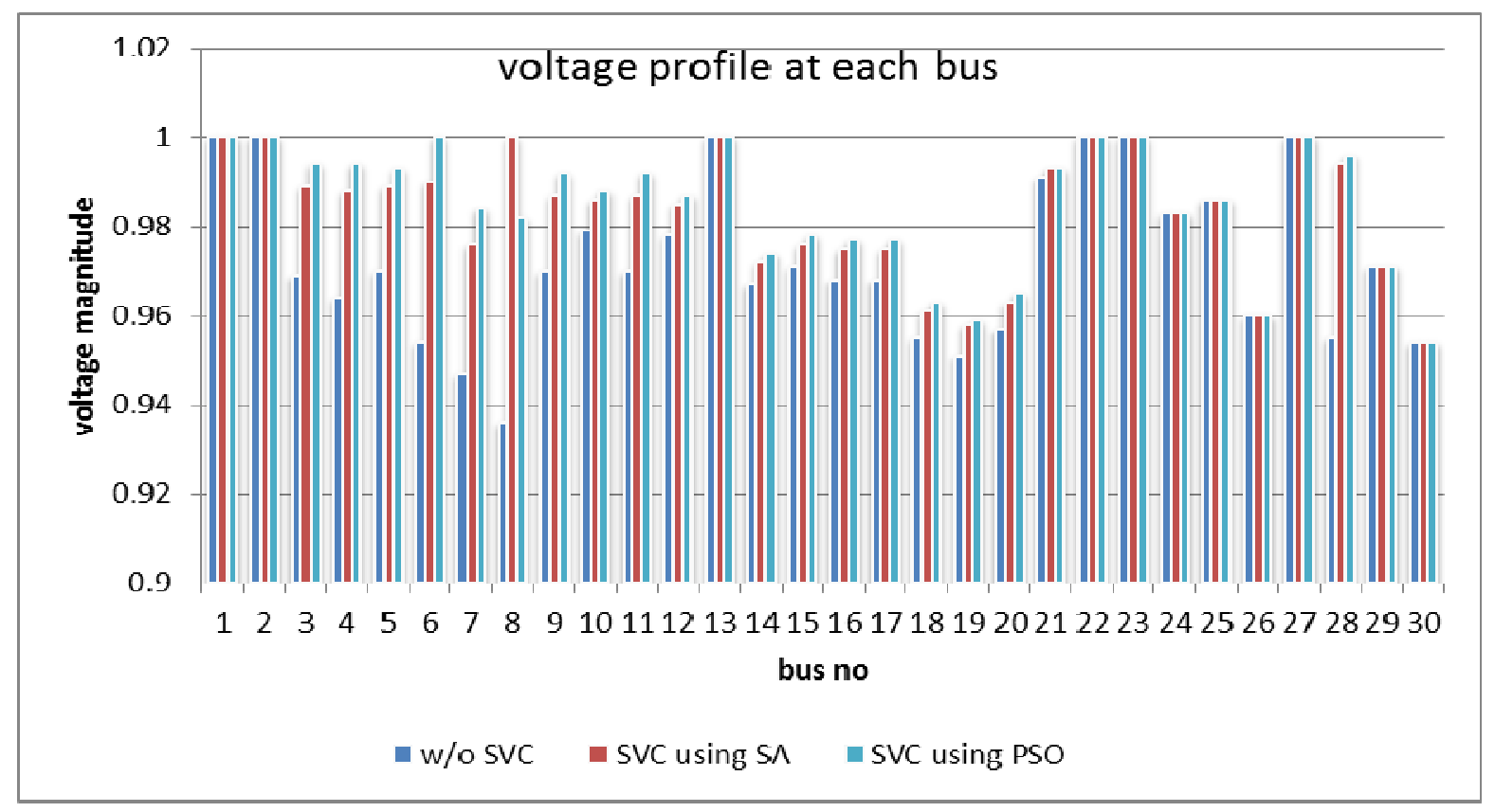

Fig. 6: Voltage Profile for All Buses

Figure 7 displays the effect of SVC at the optimal location and optimal size on the gross system losses. From this figure, Note that the presence of SVC greatly reduces losses in lines $(6,27,28$ and 29) and a slight increases power losses in lines (7, 9, 24, 25 and 26), so the overall power system losses are extremely decreased using SVC.

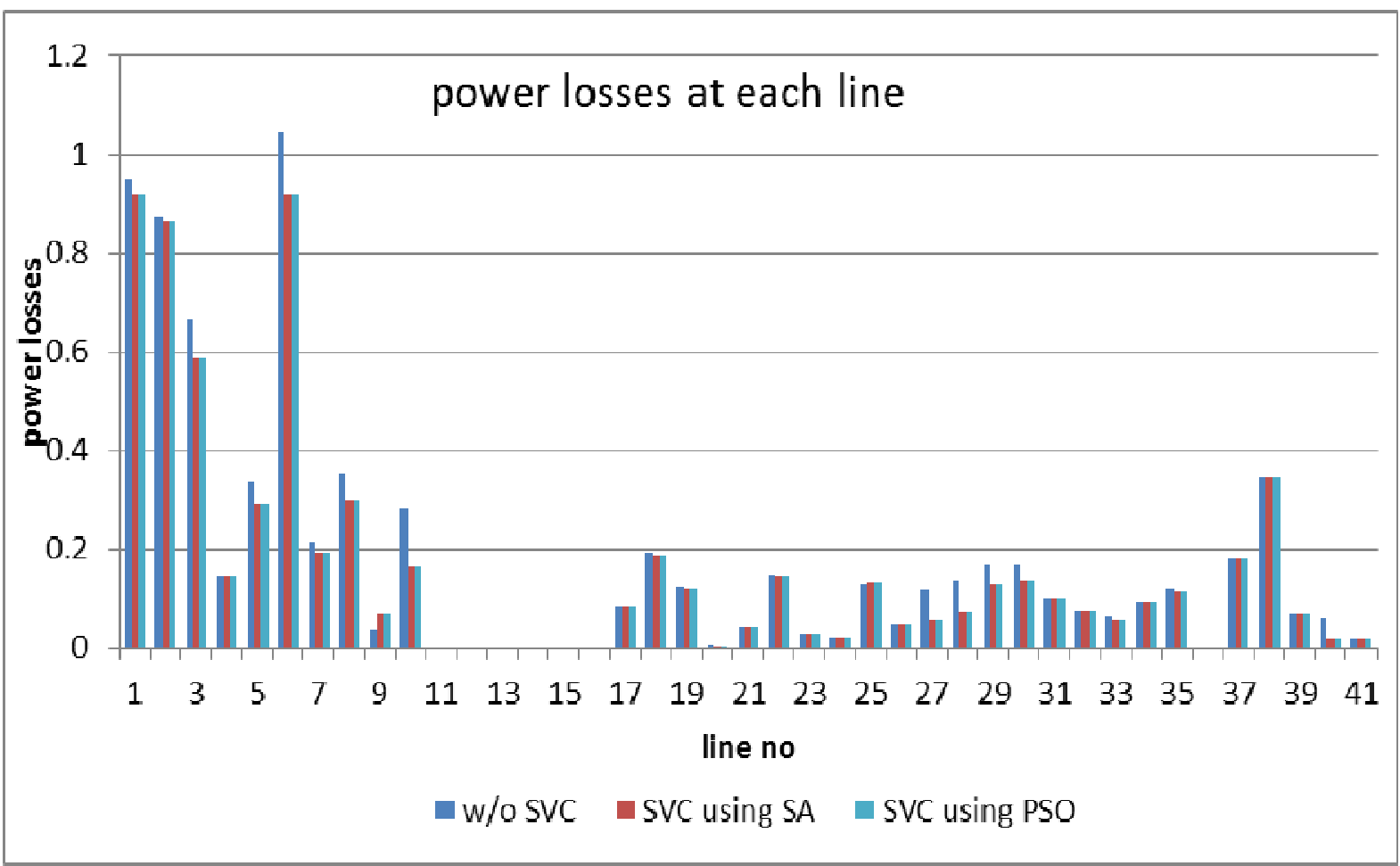

Fig. 7 Power Losses at Each Line 
Figure 8 gives a comparison between the three cases at each line to get the effect of SVC in the optimal location and optimal size on the system overload.

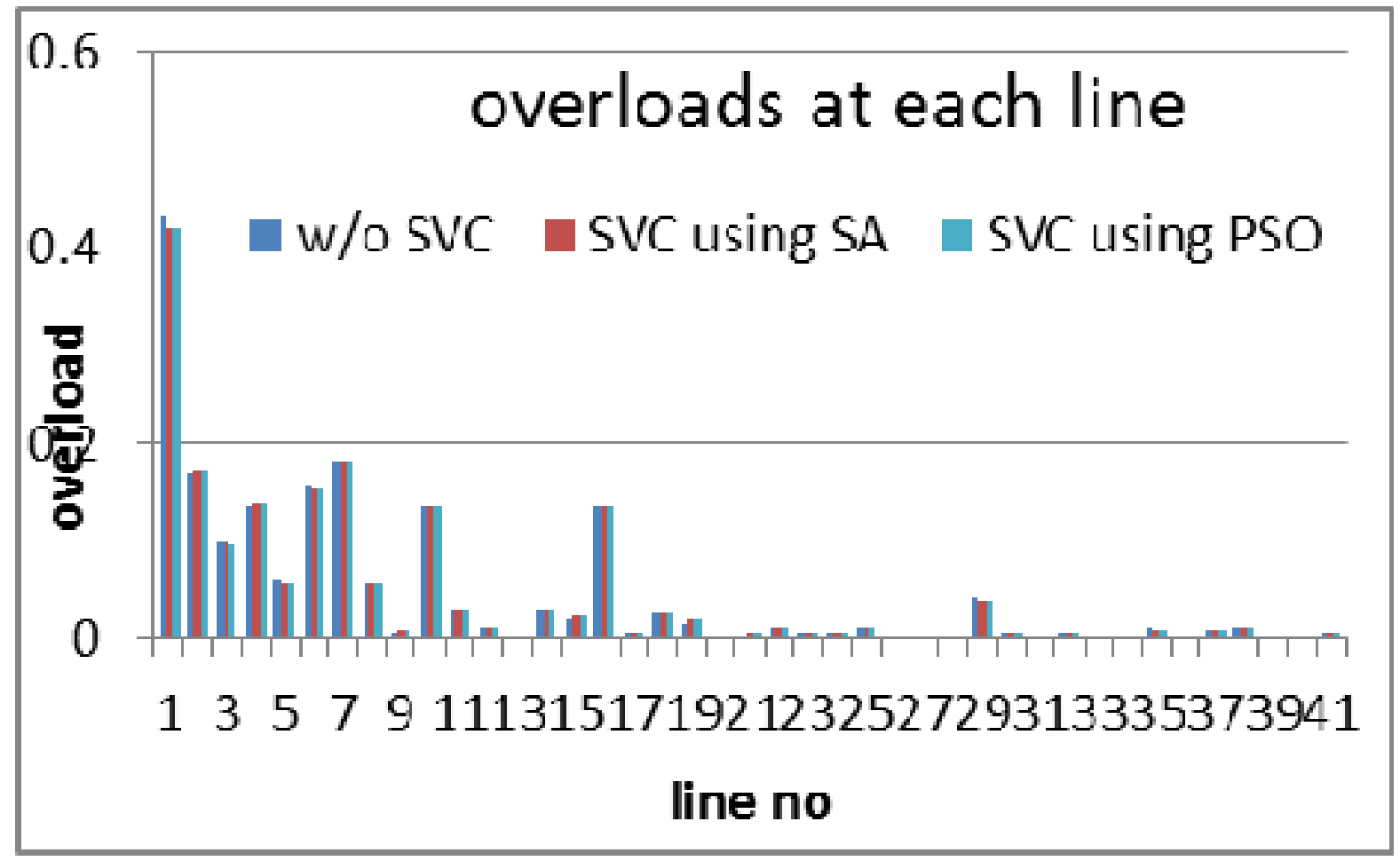

Fig 8: Overloads of Transmission Lines

From figures 6, 7 and $8 \mathrm{SVC}$ is High efficiency device which can independently or together have domination on the real power, the reactive power, and the voltage at each bus of power networks.

\section{7- CONCLUSION}

In this study, a comparison between particle swarm optimization (PSO) and simulated annealing (SA) algorithm has been carried out to find the optimal location and optimal size of SVC. From the results obtained, PSO gave better results than SA algorithm and it takes less time to run than SA. Also, in this study, a comparison between multi- and single objective function using PSO and SA algorithm has been done to find the optimal location and optimal size for SVC. From the results obtained, multi-objective function gave better results than single objective function. The outcomes discover that the SVC is so successful in decreasing losses and keep the voltage within the permissible limits in the electrical power network.

\section{REFERENCES}

1. Gaur, Dipesh, and Mathew, Lini., (2018). "Optimal Placement of FACTS Devices Using Optimization Techniques.”, A review. IOP Conference Series: Materials Science and Engineering. 331. 012023. 10.1088/1757-899X/331/1/012023.

2. Ahmed, Al Ahmed, and Reza Siriani., (2019). "Optimal Placement and Sizing of Multi-type FACTS Devices in Power Systems using Metaheuristic Optimisation Techniques.", i.asei.10.013.

3. Singh, S., and David, A.K., (2000). "Congestion Management by Optimizing FACTS Device Location" International Conference on Electric Utility Deregulation and Restructuring and Power Technologies.", pp. $23-28$.

4. Srekanth, Reddy Donapati, and Verma, M.K., (2008). "An Approach for Optimal Placement of UPFC to Enhance Voltage Stability Margin Under Contingencies.", Fifteenth National Power Systems Conference (NPSC), IIT Bombay, pp.441-446. 
5. El-arini, Mahdi,M., and Raef S.S., Ahmed, (2017). "Optimal Location of FACTS Devices to Improve Power Systems Performance.”, Journal of Electrical Engineering. Vol. 12, No.3, PP.73-80.

6. Shaheen, H.I., Rashed, G. I., and Cheng, S.J., (2007). "Application of Evolutionary Optimization Techniques for Optimal Location and Parameters Setting of Multiple UPFC Devices". Third International Conference on Natural Computation (ICNC), Vol.4, pp. 688-697.

7. Gitizadeh, M., and Kalanta, M., (2008). "A New Approach for Congestion Management Via Optimal Location of FACTS Devices in Deregulated Power Systems", DRPT 2008, Nanjing China, Vol 6, No 9, pp. 1592-1597.

8. Rashed, G. I., Shaheen, H. I., and Cheng, S.J., (2007). "Optimal Location and Parameter Settings of Multiple TCSCs for Increasing Power System Loadability Based on GA and PSO Techniques.", Third International Conference on Natural Computation (ICNC).

9. Ayman, A., Alabduliabbar, (2006). "Generation Costs Reduction Through Optimal Allocation of FACTS Devices Using Low Discrepancy Sequences.", Power Systems Conference and Exposition, PSCE '06. IEEE PES, pp. 946 - 951.

10. Husam, I., Shaheen, and Ghamgeen, I., Rashed, and S.J., Cheng. (2011). "Optimal Location and Parameter Setting of UPFC for Enhancing Power System Security Based on Differential Evolution Algorithm". International Journal of Electrical Power \& Energy Systems Vol. 33, No.1, pp. 94-105.

11. Z., Lu, M.S., Li., W.J.,Tang, and O.H., Wu., (2007). "Optimal Location of FACTS Devices by A Bacterial Swarming Algorithm for Reactive Power Planning”. IEEE Congress on Evolutionary Computation, pp. 2344 - 2349.

12. D., Radu, and Y., Bésanger, (2006). "A Multi-Obiective Genetic Algorithm Approach to Optimal Allocation of Multi-Type FACTS Devices for Power Systems Security". Power Engineering Society General Meeting, IEEE, pp. 8. doi:10.1109/PES.1709202.

13. T., Lie, and D.M., Vilathgamuwa and J., ChenTiing. (2002). "Basic Control of Interline Power Flow Controller". IEEE Power Engineering Society Winter Meeting, vol. 2, pp. $521-525$.

14. Reddy, SS., (2016). "Determination of Optimal Location and Size of Static VAR Compensator in a Hybrid Wind and Solar Power System". Int J Appl Eng Res, Vol.11, No.23, PP.494-500.

15. Gerbex, S., Cherkaoui, R., and Germond, A.J., (2001). "Optimal Location of MultiType FACTS Devices in a Power System by Means of Genetic Algorithms". IEEE Trans. on Power Systems , Vol.16, No.3, pp.537-544.

16. Kang, T., Yao,J., Duong, T., and Yang, S., (2017). "A Hybrid Approach for Power System Security Enhancement via Optimal Installation of Flexible AC Transmission System (FACTS) Devices". Energies. Vol 10, No.9, pp.1305-1337.

17. Shaheen, A.M., Spea, SR., and Abido, MA., (2015). "A Review of Meta-Heuristic Algorithms for Reactive Power Planning Problem". Ain Shams Eng J. pp.1-16.

18. Kanaan, H.A., M., EL-Sayed, S.K., and Mehanna, M.A.A., (2016). "Impact of Distributed Generator in Power System Network". International Journal of Scientific \& Engineering Research Vol 7, No 4, PP.1425-1430.

19. EL-Sayed, Salah Kamal, (2017). "Optimal Location and Sizing of Distributed Generation for Minimizing Power Loss Using Simulated Annealing Algorithm". Journal of Electrical and Electronic Engineering. Vol. 5, No. 3, pp. 104-110.

20. Clerc, M., and Kennedy.J., (2002). "The Particle Swarm-Explosion, Stability and Convergence in a Multidimensional Complex Space". IEEE Transactions on Evolutionary Computation, Vol.6, No.1, pp.58-73.

21. Niknam, T., (2009)."An Efficient Hybrid Evolutionary Algorithm Based on PSO and HBMO Algorithms for Multi-Obiective Distribution Feeder Reconfiguration”. Energy Conversion and Management. Vol 50, No.8, pp. 2074 - 2082. 